\title{
CONVENTIONAL FUEL TANK BLUNT IMPACT TESTS: TEST AND ANALYSIS RESULTS
}

\author{
Karina Jacobsen \\ Michael Carolan \\ Benjamin Perlman \\ Volpe National Transportation Systems Center \\ United States Department of Transportation \\ Cambridge, Massachusetts, USA
}

\section{ABSTRACT}

The Federal Railroad Administration's Office of Research and Development is conducting research into fuel tank crashworthiness. A series of impact tests are planned to measure fuel tank deformation under two types of dynamic loading conditions - blunt and raking impacts. This paper describes the results of the first set of blunt impact tests for two retired EMD F-40 locomotive fuel tanks, Tank 232 and Tank 202.

On October 8, 2013 and October 9, 2013, the FRA performed impact tests on two conventional passenger locomotive fuel tanks at the Transportation Technology Center (TTC) in Pueblo, Colorado. Each fuel tank was emptied of fluid and mounted on a crash wall with the bottom surface exposed. A rail cart modified with a "rigid" indenter was released to impact the center of the bottom of each fuel tank at about $6 \mathrm{mph}$. A center-impact on Tank 232 was chosen to impact between two baffles. A center-impact on Tank 202 was chosen to impact on a baffle.

In the first test, Tank 232 was impacted by the indenter at $4.5 \mathrm{mph}$. The maximum residual indentation on the bottom of the tank measured approximately 5 inches. The tank deformed across the middle longitudinal span of the tank forming a diamond-shaped indention. In the second test, Tank 202 was impacted by the indenter at $6.2 \mathrm{mph}$. The maximum residual indentation on the bottom of the tank measured approximately 1.5 inches. The bottom of the tank deformed with an " $X$ " shape spanning out from the location of square indenter at the center of the tank.

Post-test autopsies revealed the deformation of the interior structures, i.e. baffles and attachments. There was no damage to the baffles in Tank 232. Deformation to the interior structure of
Tank 202 was limited to the baffle directly beneath the impact location, which folded in the area near the impact location. Material coupons were cut and tensile testing performed to determine the properties of the materials used in each tank.

Prior to the test, computer models were developed from measurements taken on the test articles. Material properties were estimated based on Brinell hardness measurements. Computer analyses were conducted to determine the conditions for the test, i.e. instrumentation, location of impact, target impact speeds and to predict the deformation behavior of the tank. Post-test, the resulting stress-strain relationships for the bottom sheets and baffles of both tanks were used to update the finite element models of the two tanks. The models were also updated to reflect the actual geometry of the tanks as confirmed by measurements of the tank interiors. The results of the finite element (FE) models run at the test conditions with the updated tank details are compared with the results from the test itself. Specifically, the deformation progression and the residual dent depth are compared between the tests and the models.

In accidents, fuel tanks are subjected to dynamic loading, often including a blunt or raking impact from various components of the rolling stock or trackbed. Current design practice requires that fuel tanks have minimum properties adequate to sustain a prescribed set of static load conditions. Current research is intended to increase understanding of the impact response of fuel tanks under dynamic loading.

\section{INTRODUCTION}

Fuel tank crashworthiness research is being conducted as part of the Federal Railroad Administration's (FRA's) 
Equipment Safety Research program. The crashworthiness research efforts follow the methodology illustrated in Figure 1, which begins with developing a baseline measure of existing design performance for a given scenario and extends to developing improvements for enhancing safety performance for that scenario. The current stage of research is focused on evaluating existing fuel tank designs under dynamic impacts.

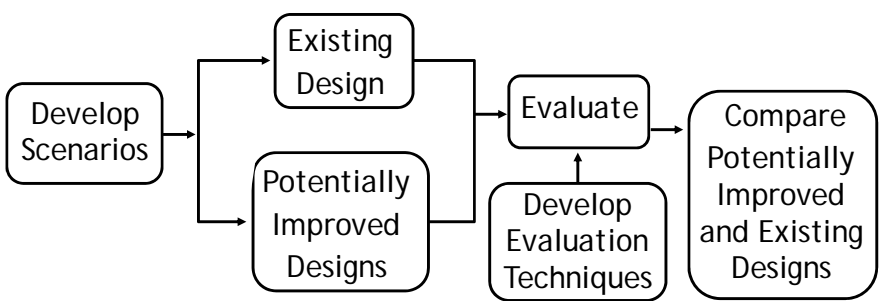

Figure 1. Flow Diagram of Crashworthiness Research Methodology

The event of a fuel tank rupture during a train collision or derailment may result in fire, which presents additional threats to the survivability of passengers and crew as they egress from the collision wreckage. A paper surveying accidents and derailments in the U.S. over the last two decades, summarizes the results of an accident survey conducted under FRA research [2]. Each scenario can be categorized by its resultant loading type and there are two general loading conditions leading to punctures: blunt impacts and raking impacts.

The current FRA research on fuel tank integrity focuses on evaluating the identified types of dynamic impacts for fuel tanks and investigating how fuel tank design features (such as baffle placement) affect the overall integrity of the tank. Research activities include analytical modeling of fuel tanks under dynamic loading conditions, dynamic impact testing of fuel tank articles, and development of recommendations for improved fuel tank protection strategies.

Understanding the dynamic response of fuel tanks under idealized impact conditions will guide development for design requirements that allow for a variety of fuel tank designs with a baseline level of integrity. A series of fullscale tests is planned to simulate blunt and raking impacts of various fuel tank designs.

One key output of this series of full-scale tests is to understand the deformation pattern of a fuel tank under dynamic impact loads. The particular design features of the fuel tank affect the behavior of the tank when loaded. Through testing, the dynamic response of the tank can be observed, measured and documented. Comparing the test results of pretest modeling and analyses helps to refine the models. Models can then be used to vary parameters both of the tank features and the impact conditions to better understand the range of impact behavior of that specific tank design. For example, the impact location can be varied to examine the tank's response to impacts at various places on the surface of the tank. Extrapolations can then be made for other fuel tank designs which may include different design features, e.g. size, shape, baffle configuration, stiffeners, material properties, etc.

\section{BLUNT IMPACT TEST SCENARIO}

The preliminary testing of conventional fuel tanks was conducted on October 8-9, 2013 at the TTC in Pueblo, Colorado. A blunt impact was imparted to two fuel tank designs. Each test was intended to simulate a rigid impactor striking the bottom surface of the tank. The target impact speeds were chosen to impart sufficient energy to the tank to result in permanent deformation.

\section{Objective}

The key objective of the impact testing of fuel tanks is to examine the gross response of the fuel tanks with a given impact type. For the blunt impact tests the objective is to characterize each fuel tank's deformation behavior when impacted on the bottom sheet. The overall approach to characterizing the deformation behavior includes:

1. Apply a blunt, dynamic load to the bottom surface of a fuel tank to deform the fuel tank.

2. Measure the force-deflection behavior of the tank with specified instrumentation.

3. Record mode of deformation with high-speed and conventional video cameras.

The results can be used to make a comparison with analysis techniques being used to provide addition information on the fuel tank behavior of different designs. The results of the first two impact tests, described in this paper, show the pros and cons of the current test setup and can be used to improve the test setup for additional tests. Because the series of fuel tank tests planned in this research program will be destructive tests, it is important to have a thorough understanding of the test setup, instrumentation needs, and test parameters before conducting tests on DMU fuel tanks or tanks of an alternative design.

\section{Test Setup}

The impact scenario for the blunt impact tests of two conventional fuel tanks is illustrated schematically in Figure 2. The tank was aligned for an impact to the center bottom surface of the tank by mounting it to a vertical crash test wall. A rail cart was fitted with a rigid 12-inch by 12-inch impactor. The impact cart was set to roll along the tracks at a prescribed speed to impact the bottom of each fuel tank with the desired impact force.

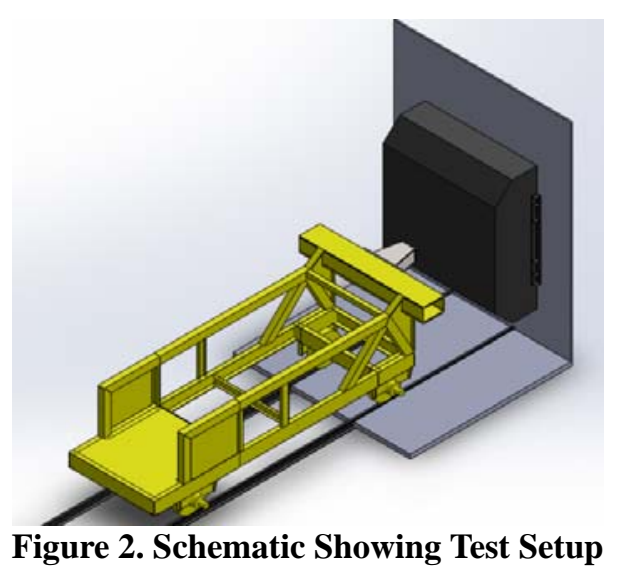




\section{IMPACT CART}

Figure 3 shows the impact cart used to impart the dynamic impact. An impacter head was designed and mounted to the main horizontal cross-member of the cart, aligned to impact the center of the bottom surface of the fuel tanks. The indenter was designed to be more rigid than the fuel tank. The cart was equipped with air brakes that would trigger when the sealed PVC pipe impacted a stake in the ground just prior to contact with the tank. The brakes take 1-2 seconds to engage allowing the significant part of the impact to progress before the cart slows down upon rebound from the wall. The data bricks were secured to the rear surface of the cart. The trigger for the instrumentation was located between the front two wheels and occurred upon impact with a stake in the ground.

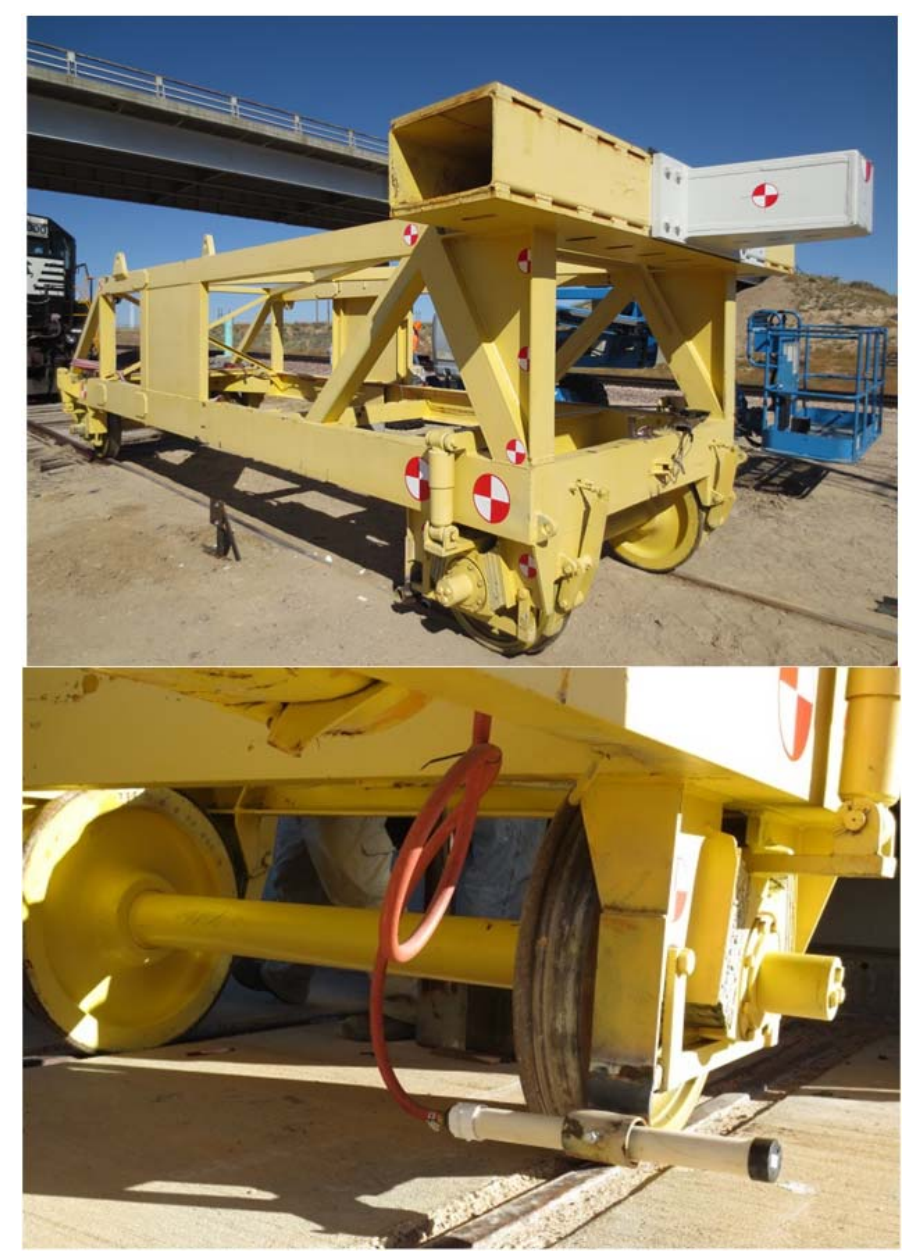

Figure 3. Photos of the Impact Cart (top) and the Air Brake Trigger behind the Front Right Wheel (bottom)

\section{CRASH WALL}

The crash wall was prepared with fuel tank mounts as shown in Figure 4. 2-inch thick steel was welded to the wall with holes tapped at the location of the fuel tank attachments. The wall mounts allowed for the fuel tank to be secured using existing fuel tank attachments and allowed for time-efficient installation and removal of the fuel tanks, i.e. 1 hour.

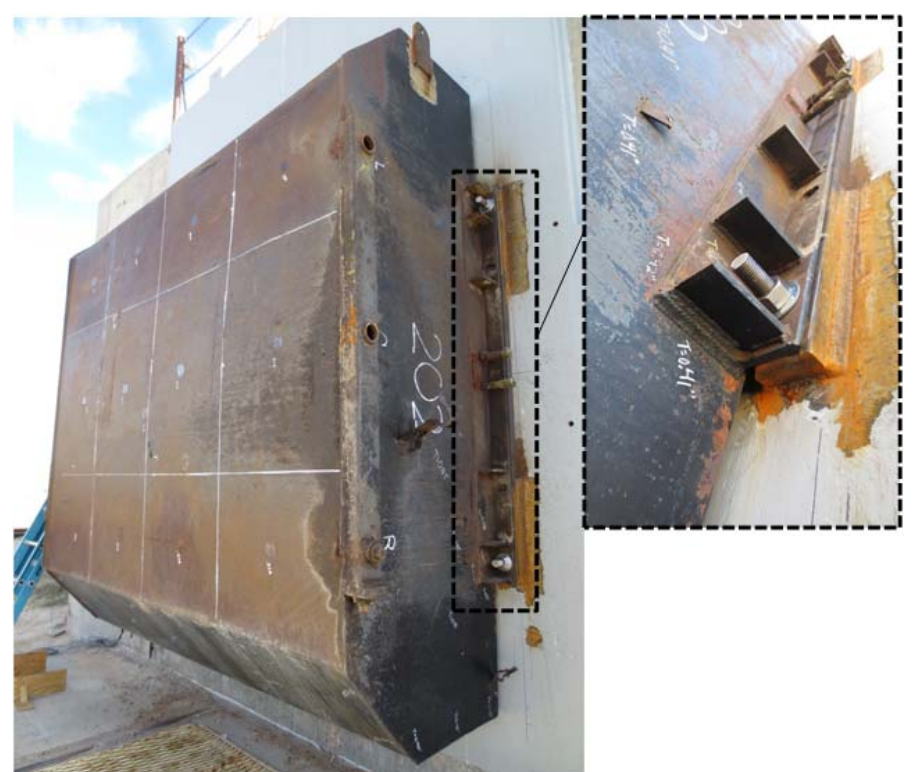

Figure 4. Photo of Crash Wall Mounts for Tank 202

\section{INSTRUMENTATION}

Instrumentation was placed on the cart and surrounding environment to obtain data to characterize the fuel tank behavior and to assess the details of the test setup in creating a controllable dynamic impact condition. Table 1 describes the location and purpose of accelerometers, speed transducers and cameras used in each impact test. Figure 5 shows the views of each camera. The red lines indicate a high speed camera and the green lines indicate a normal speed camera.

Table 1. Instrumentation for Each Impact Test

\begin{tabular}{|c|c|c|}
\hline Measurement Type & Location & Quantity \\
\hline Speed & Mounted on impactor vehicle & 2 \\
\hline Accelerometers & Mounted on impactor vehicle & 5 \\
\hline High speed video & Adjacent to track & 3 \\
\hline Normal speed video & Adjacent to track & 3 \\
\hline
\end{tabular}

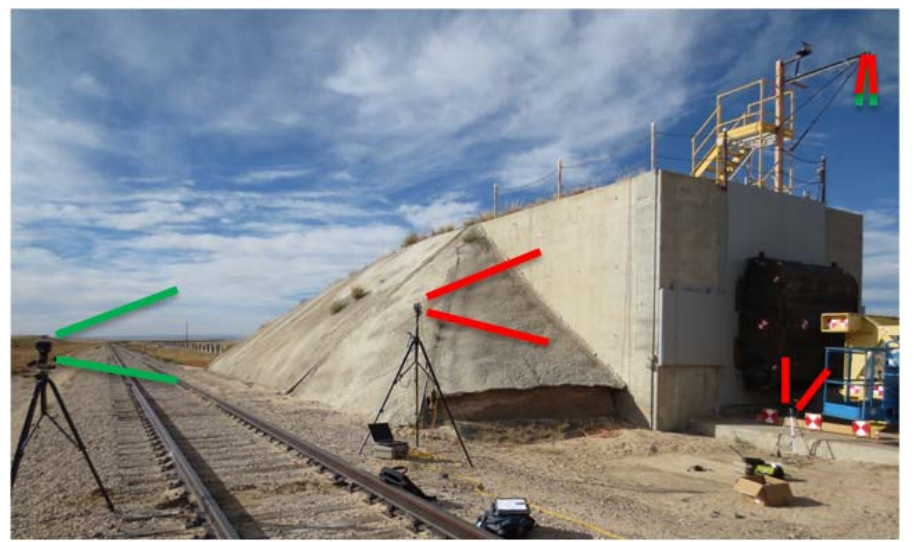

Figure 5. Photo of Test Setup Showing Placement of Cameras 


\section{TEST SPECIMENS}

Two conventional passenger locomotive fuel tanks, retired from operation were used for testing. These tanks are from F40 type locomotives and are referred to as locomotives 202 and 232. While the locomotives are similar and previously used in passenger service, the two fuel tanks taken from these locomotives have distinctively different, but typical design details, most notably shape, internal baffle layout and material properties.

While these test articles are not current in design detail or construction, the fuel tanks, each 1800-gallon capacity, are typical in size for a conventional passenger fuel tank and were deemed suitable for these preliminary tests of a dynamic impact scenario. The tanks provide the types of data needed to test the test setup and lay out a future series of tests, eventually leading to testing alternative fuel tank designs such as DMU fuel tanks. As these tanks were collected from locomotives already donated to FRA and available at TTC, the overall cost and schedule for the preliminary tests were minimized.

Figure 6 has photos of Tank 202 and 232 mounted to the wall prior to testing. Tank 202 has a roughly trapezoidal-cross section, while Tank 232 has a rounded shape. White chalk lines drawn on the exterior indicate the approximate location of the internal baffles.

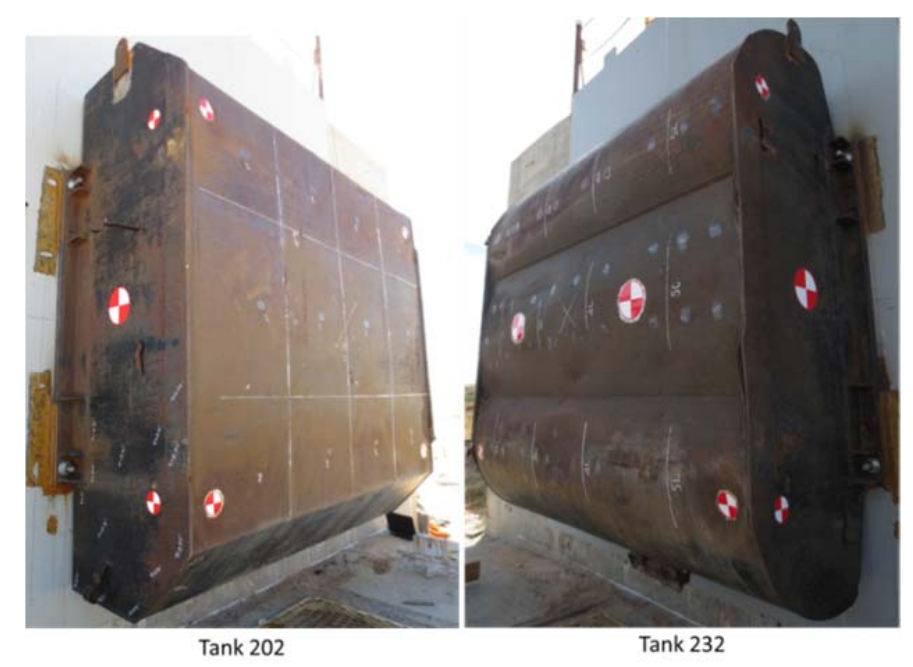

Figure 6. Fuel Tank 202 (left) and 232 (right)

Detailed information on the geometry and material hardness of the two fuel tanks was measured by Transportation Technology Center Inc. (TTCI) prior to the test, using nondestructive techniques to estimate the interior configuration of the tank baffles and estimate the material properties of the exterior structure. This information included the overall dimensions of the tanks, the thicknesses of the sheets making up the exterior of the tanks, the placement of the lateral and longitudinal baffles in the tanks' interiors, the thickness of the baffles, and the approximate arrangement of the baffles, including the holes and cutouts within the baffles.

Hardness measurements were used to estimate the yield and ultimate strengths of most materials in each fuel tank. The material and thickness properties used as inputs to the pre-test finite element (FE) models are referenced in a previous paper on test requirements [4]. Following the test, material coupons from the fuel tank were cut and submitted for tensile tests to determine the stress-strain behaviors. The pre-test FE models were updated with these properties.

In addition to the obvious external differences between the two tanks, the internal arrangement of the baffles also differs. Figure 7 shows four images taken from the FE models of tanks 202 and 232.

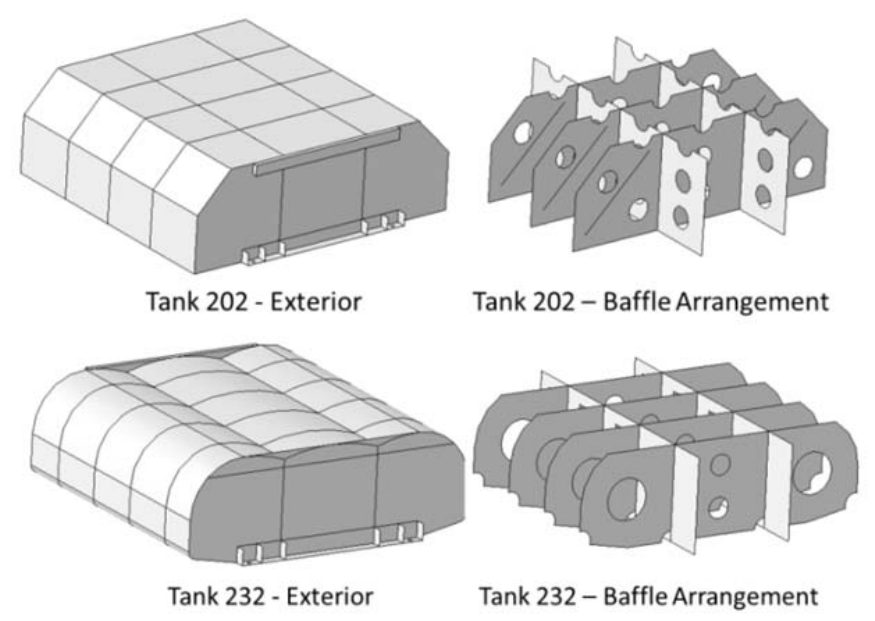

Figure 7. Exterior and Interior Views of Tanks 202 and 232 (From FE Model)

\section{TEST RESULTS}

On October 8, 2013 and October 9, 2013, a blunt impact test was conducted on Tank 232 and Tank 202, respectively, at the TTC in Pueblo, Colorado. In the first test, Tank 232 was impacted at the approximate center of the bottom tank surface by the indenter at $4.5 \mathrm{mph}$. The maximum residual indentation on the bottom of the tank measured approximately 5 inches. The tank deformed across the middle longitudinal span of the tank into a diamond-shaped indention. In the second test, Tank 202 was impacted at the approximate center of the bottom tank surface by the indenter at $6.2 \mathrm{mph}$. The maximum residual indentation on the bottom of the tank measured approximately 1.5 inches. The bottom of the tank deformed with an " $X$ " shape spanning out from the location of square indenter at the center of the tank.

The key results compared between the two tests are the observed structural deformation of the exterior and interior of each tank and the measured acceleration-versus-time behavior of the cart during each impact.

\section{STRUCTURAL RESULTS}

\section{Tank 232}

Figure 8 shows photographs of the tank before and after the blunt impact. The residual indention is most pronounced at the point of impact from the indenter. The maximum depth is 5 inches. 


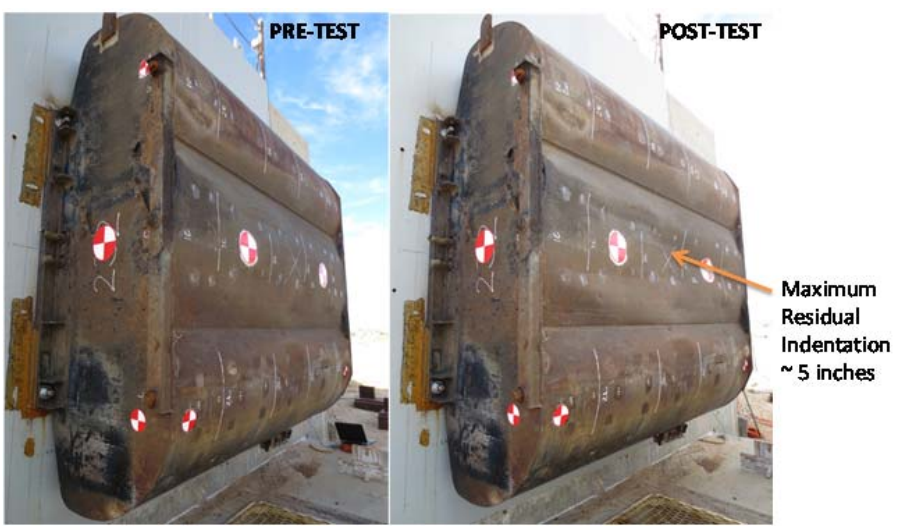

Figure 8. Tank 232 Pre-test (right) and Post-test (left)

Tank 232 experienced a diamond-shaped dent across its center section due to the center impact from a 12" by 12 " square-shaped indenter head. Figure 9 shows a view of the tank post-test with the dent shape highlighted. The deepest residual dent is at the center, at the location of indenter, measuring approximately 5 inches. The deformation was confined to the center billow. The two adjacent billows of the tank, above and below, showed no deformation from the blunt impact at the center of the tank.

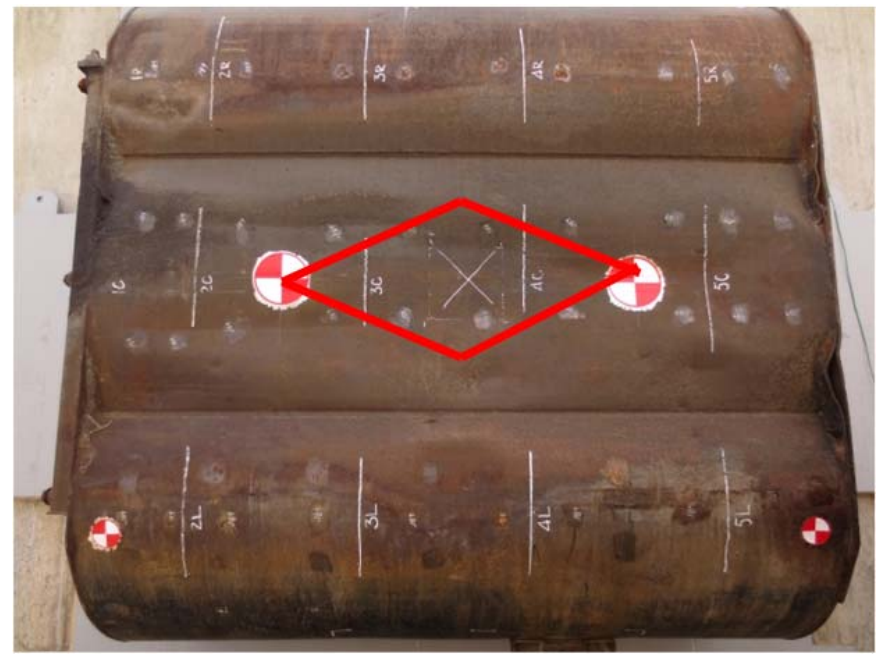

Figure 9. Post-test Dent Shape, Tank 232

Post-test tank autopsies were conducted to document the deformation behavior of the interior structure. The indenter impacted the center of the fuel tank, which for Tank 232, is about halfway between two horizontal baffles. This is a 5-inch gap between the bottom surface of the tank and the baffles. Upon inspection, the two horizontal baffles adjacent to the impact had markings about 5-7 inches long indicating that the bottom sheet deflected enough to just make contact with the ledge of the two baffles.

\section{Tank 202}

Figure 10 shows photographs of the tank before and after the blunt impact. The residual indention is most pronounced at the point of impact from the indenter. The maximum depth is 1.5 inches at the point of impact.

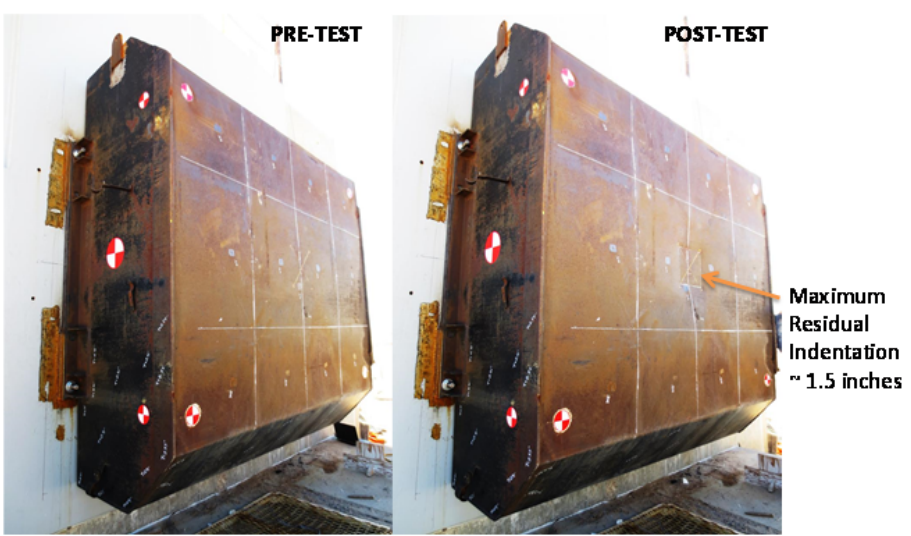

Figure 10. Tank 202 Pre-test (right) and Post-test (left)

Tank 202 experienced a shallow X-shaped deformation radiating out from the pronounced square dent at the impact zone. The " $X$ " shape spans across the continuous single sheet that makes up the bottom of Tank 202. Figure 11 shows a photograph with the deflection pattern highlighted.

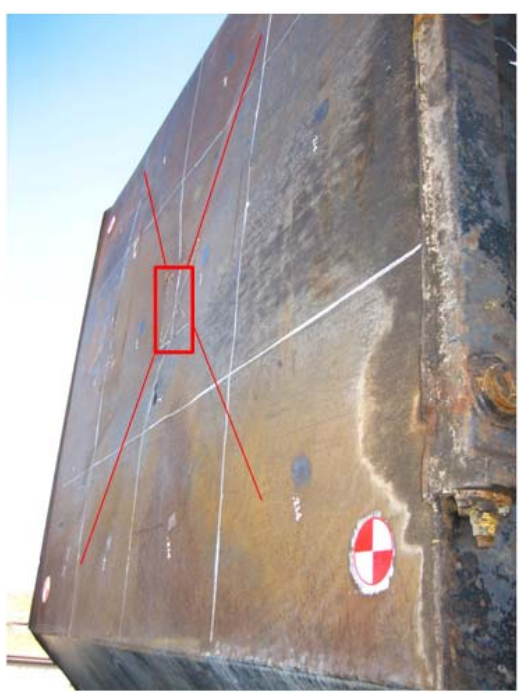

Figure 11. Post-test Dent Shape, Tank 202

A post-test autopsy of Tank 202 showed the behavior of the interior structure to the blunt impact. Tank 202 was constructed with the baffles attached to the inner surface of the bottom sheet with a series of tack welds. Due to the layout of the baffles, a center impact of Tank 202 impacts directly on a baffle. During the test, the baffle directly beneath the impactor showed localized buckling within a few inches of the bottom sheet.

\section{ACCELERATION DATA}

For both tanks, examination of the acceleration-time history measured by each accelerometer on the impact cart indicated a fairly noisy response by the cart. It appears that the impact cart was not as rigid as had been expected. While this does not invalidate the acceleration data measured at each location on the cart, it prevents the assumption that the cart may be approximated as a rigid body with its mass located at a 
single point. Therefore, the acceleration measurements themselves will be discussed throughout the remainder of this paper, as opposed to the impact force derived by multiplying the full mass of the cart by its longitudinal acceleration.

Acceleration data was collected for the impact cart during both tests. Figure 12 compares the longitudinal response of the both tanks to the test impacts. It is apparent from this figure that each tank responded to the impact differently. The response of each tank is discussed following the figure.

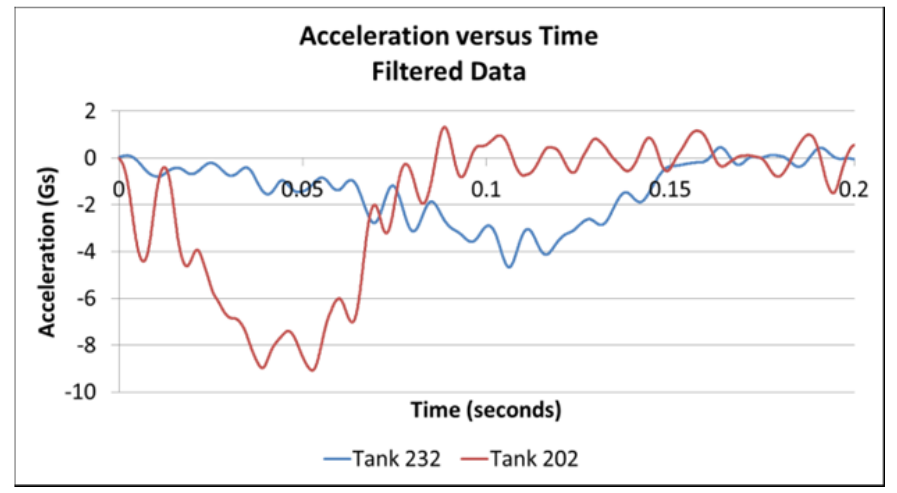

Figure 12. Acceleration-time History for Both Tanks

Impact with Tank 232 resulted in a longer-duration, lessermagnitude deceleration of the impact cart. The change in slope that occurs between 0.05 and 0.1 seconds may be attributed to stiffening of the tank that occurs when the bottom (impacted) sheet closes the internal gap between it and the baffles. After slightly more than 0.1 seconds, the impact cart has stopped moving forward and is rebounding back as Tank 232 recovers its elastic energy.

As seen in this previous figure, Tank 202 behaved very differently than Tank 232. In Tank 202, there is an initial deceleration associated with buckling of the baffle directly beneath the impacted location. Following this buckling, the acceleration climbs at a high rate, as the load is being transmitted through the bottom sheet directly into the baffles in this tank. By approximately 0.05 seconds, the impact cart has come to a stop and is now being rebounded as the tank recovered its elastic energy. By approximately 0.1 seconds, the impact event had ended for Tank 202.

\section{ANALYTICAL COMPARISONS}

Finite element analyses have been used to assist in planning the impact tests. FE analyses of both Tanks 202 and 232 have been performed. Impact from a 12" by 12 ” impactor has been simulated for an impact with each tank. Additional FE analyses have been conducted on the impact cart in its current configuration. These analyses were performed both to ensure that the impact cart will not experience permanent deformation during the test as well as to assess the likelihood that the cart will lift off of the rails during the impact test.

\section{Pre-test Results}

Prior to the impact tests, finite element analysis (FEA) was performed of each tank. The pre-test models were discussed in previous publications [4]. These models used material properties estimated from hardness measurements made on several outer surfaces of the tank. Additionally, the internal baffle layout was estimated for both tanks. Based upon posttest measurements, it was determined that several changes needed to be made in order to reflect the actual geometry of the tanks. Those changes will be discussed in the following section.

The acceleration-time histories from the pre-test models are shown in Figure 13 for both tanks. The pre-test models predicted very different qualitative behaviors from both tanks. The primary difference for this difference in behavior is a result of the internal baffle arrangement of each tank. In Tank 232, the baffles are arranged in such a way that a centered impact will strike the bottom sheet between baffles. Because there is a gap between the inside of the bottom sheet and the bottom of the baffle to permit fuel to flow, the impact response is initially soft. Once the gap has been closed, the impactor loads the baffles directly and the tank response becomes stiffer. Tank 202 features a baffle welded directly to the inside of the bottom sheet at the center of the tank. For a center impact on this tank, the baffle engages immediately and quickly buckles. The postbuckling response is still stiff compared to Tank 232, as the baffles of Tank 202 are attached directly to the bottom face sheet.

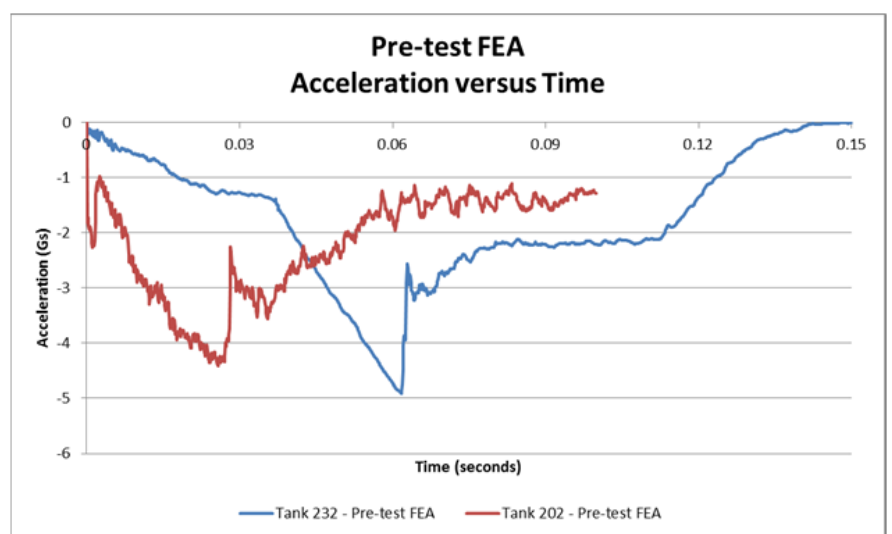

Figure 13. Acceleration versus Time for Both Tanks, Pretest FEA

\section{Updates to Finite Element Model}

After each impact test the subject tank was cut open to permit inspection of both the exterior and interior of the tank. In addition to documenting the damage that occurred to each tank, this inspection permitted measurement of interior tank features that were difficult to measure prior to the test. The post-test FE model was updated to reflect differences that were found between the tested article and the pre-test model. Additionally, the FE model of each tank was updated with material thickness and stress-strain behavior obtained through tensile testing following the impact tests. Finally, the FE models were updated to more closely reflect the actual impact conditions, such as the actual impact speed measured during each test.

Review of the acceleration-time data from the tests indicated that the impact cart may have been more flexible than originally anticipated, introducing some additional flexibility 
into the overall cart-tank-wall system. A model of a deformable cart was incorporated into post-test models to evaluate the effect of lumping the cart mass into a rigid impactor versus distributing the mass through the cart and allowing the cart to deform in response to the impact. This model was based upon FE models of this cart developed during a previous research program [5].

The boundary conditions attaching the tanks to the wall were adjusted in the model to be more similar to those in the physical test. In the pre-test models, both tanks were attached to the wall through zero-displacement boundary conditions at the nodes on the circumference of each of the four bolt holes normally used to suspend the tank beneath the locomotive. In the post-test model, these boundary conditions were removed. A rigid part representing the bolt and washer was introduced into each bolt hole. These parts would prevent the tank from moving away from the wall or from moving laterally without introducing an artificial restriction on the motion that the physical bolts would be unable to introduce. The pre- and posttest models are shown in Figure 14.

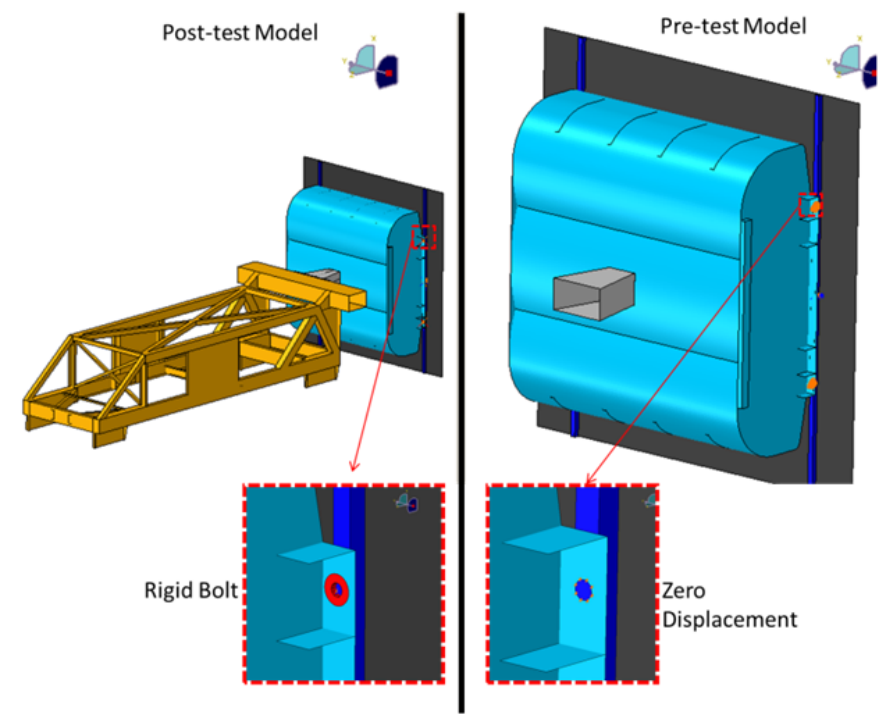

Figure 14. Post- (Left) and Pre- (Right) Test FE Models (Tank 232 Shown)

In Tank 232, the tank features a rounded bottom surface. Pre-test measurements indicated that the lateral baffles did not span the full height of the tank's interior, but stopped 3" above the bottom of the tank, presumably to permit fuel to flow beneath each baffle. Post-test measurements indicated that this gap was approximately 5" in the actual tank. Note that this is an approximate measurement, as the bottom of the tank had already experienced deformation from the test by the time the measurement was taken. Additionally, the spacing between baffles was updated to reflect the spacing in the actual tank.

In Tank 202, several differences in the connections between the baffles and the outer surfaces of the tank were noted. In the actual tank, the baffles do not span the full height of the tank's interior. Rather, the baffles terminate approximately 1.25 " above the bottom surface of the tank. This gap is spanned by an L-shaped section, with a weld between this section and both the baffle and the bottom sheet of the tank.
At the top of the tank, the baffle is in contact with the top sheet of the tank, but is not attached. These features were updated in the post-test FE model.

Following examination of each tank, areas of each tank were identified for cutting material coupons to be used in tensile tests. TTCI cut samples from Tank 232's bottom (impacted) sheet, a longitudinal baffle, and a lateral baffle. TTCI cut samples from Tank 202's bottom (impacted) sheet and a baffle. The stress-strain behavior of three material coupons from each location was measured over the full range of behavior, up to fracture of the coupon. Because each material location exhibited a high level of repeatability from sample-to-sample, the average of the three stress-strain curves was used as the input to the post-test FE model. The average stress-strain curve for each material is shown below, in Figure 15. Note that this figure displays true stress as a function of plastic strain, as this is the format input to the Abaqus FE model [6].

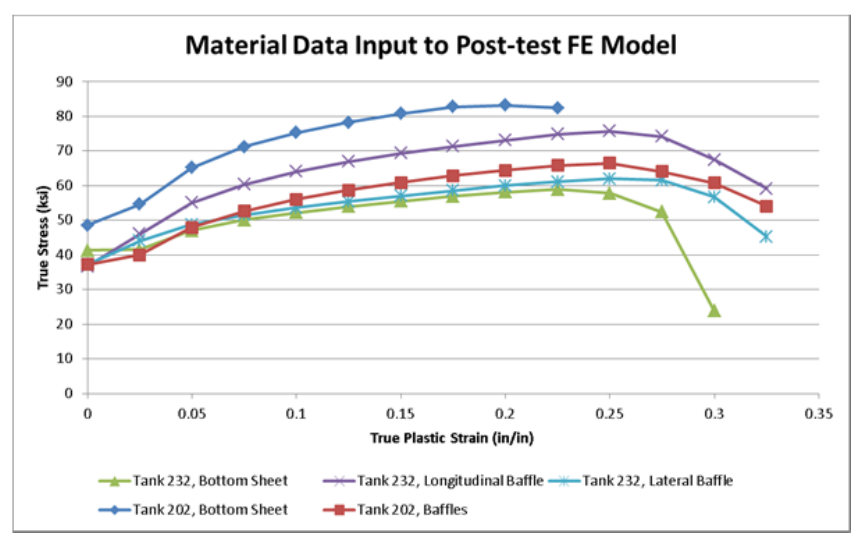

Figure 15. Stress-strain Behavior for Materials in Tanks

\section{Post-test FEA Results}

The raw test data received from TTCI has had several corrections applied to it before being plotted. Because some accelerometers were exhibiting oscillation about a non-zero acceleration prior to impact, the average of the longitudinal acceleration from 1 second before impact was subtracted from each accelerometer channel. This data was then filtered using one of the filters built-in to the Abaqus FE software [6]. The filter used was a two-pass, zero phase shift, second-order Butterworth filter with a cutoff frequency of $60 \mathrm{~Hz}$.

Finally, the acceleration-time data from each channel was integrated to produce the velocity-time data for that channel. The cart's speed, as measured by the speed trap 0.5 ” prior to impact, was used to solve for the constant of integration. Finally, the velocity-time data was integrated to produce the displacement-time data. The displacement data has its zero position at the time when the tape switches are triggered, indicating that contact between the impactor and the fuel tank has occurred. The post-test FE results are plotted against test data in the following figures.

\section{Tank 232}

The post-analysis deformed shape of Tank 232 is shown in Figure 16. Contours in this figure are of deformation in the 
direction of impactor travel (i.e. the longitudinal direction) in inches. The deformed shape from the FEA resembles the posttest shape observed in Tank 232 and shown in Figure 9. In both the test and the post-test FEA, there is a clear impression of the $12 \times 12$ square impactor head at the location of the impact. The indentation in Tank 232 extends primarily across the width of the tank (i.e. in the y-direction as shown in Figure 16). The baffles in this direction are welded directly to the bottom of the tank, whereas the baffles in the perpendicular direction have an approximate 5-inch gap between the bottom of the tank and the bottom of the baffle. Therefore, it is easier for the tank to deform along this direction compared with the perpendicular direction. The result is a diamond-shaped indentation.
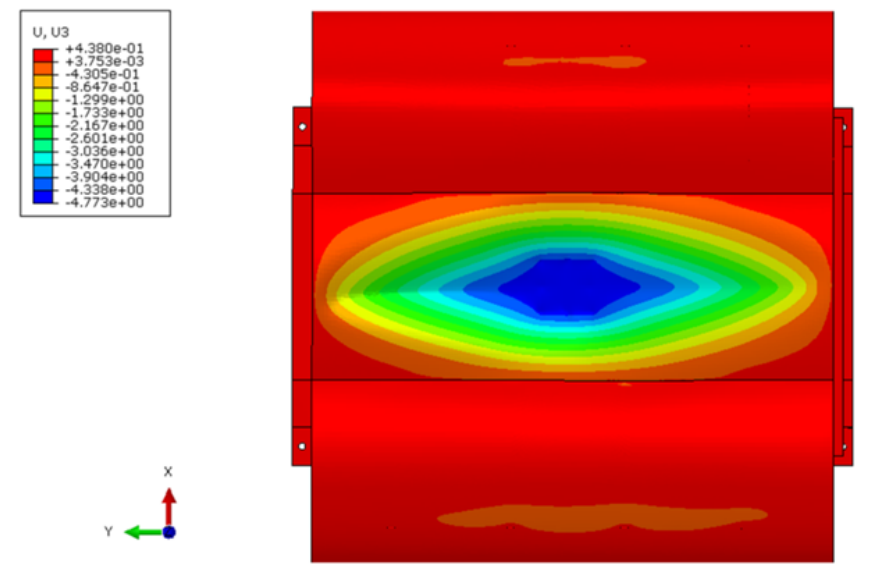

Figure 16. Residual Dent in Tank 232, Post-test FEA

The acceleration-versus-time history from the left side sill accelerometer, BA2LX, is compared between the test and the post-test FE model using the deformable cart in Figure 17. There is relatively good agreement between the two sets of results. Both the test data and the FE output have been filtered using the same filtering algorithm. As can be seen in this figure, some ringing remains in the data after this filtering. Both the qualitative behavior and the maximum deceleration are consistent between the test result and the FE model for Tank 232.

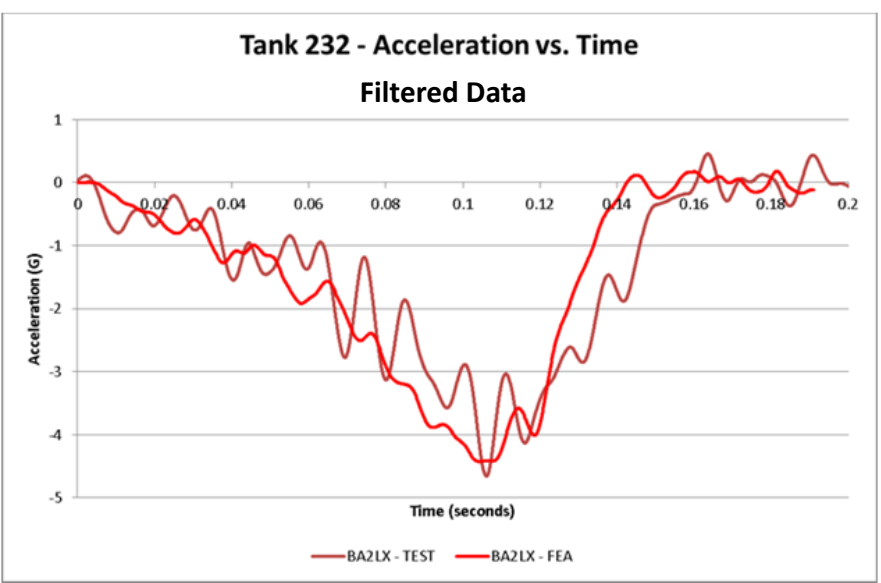

Figure 17. Acceleration versus Time, Tank 232 Test and FEA (Post-test)
Figure 18 shows the displacement versus time data from the test plotted against the displacement versus time calculations from the FE model for the same accelerometer, BA2LX. There is good agreement between the two results. The maximum displacement in the test data is approximately 6.6 inches, and the maximum displacement calculated by the FE model is approximately 6.3 inches. This difference is within $5 \%$ of the measured value.

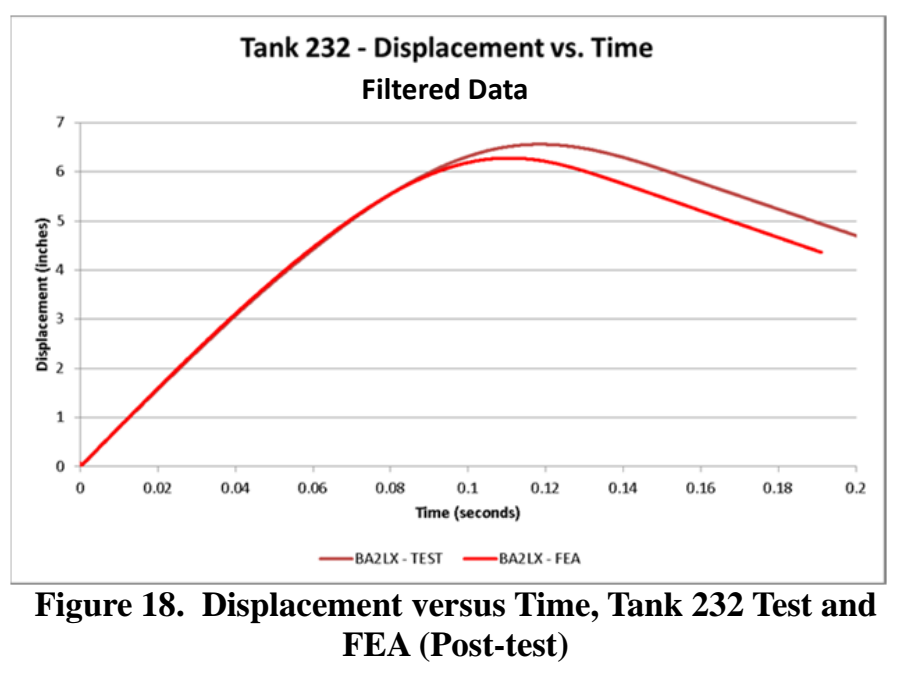

Tank 202

The post-analysis deformed shape of Tank 202 is shown in Figure 19. Contours in this figure are of deformation in the direction of impactor travel (i.e. the longitudinal direction) in inches. The deformed shape resulting from the FEA resembles the post-test shape observed in Tank 202 and shown in Figure 11. In both the test and the post-test FEA, the dent roughly conforms to the square impactor shape in the area around the impact site. Outside of this immediate region, the dent is roughly X-shaped. This behavior can be attributed to the intermittent pattern of welds between the baffles and the bottom sheet of this tank. Where the bottom sheet is welded to the baffles the indentation is smaller, as the baffle provides increased stiffness at these locations.

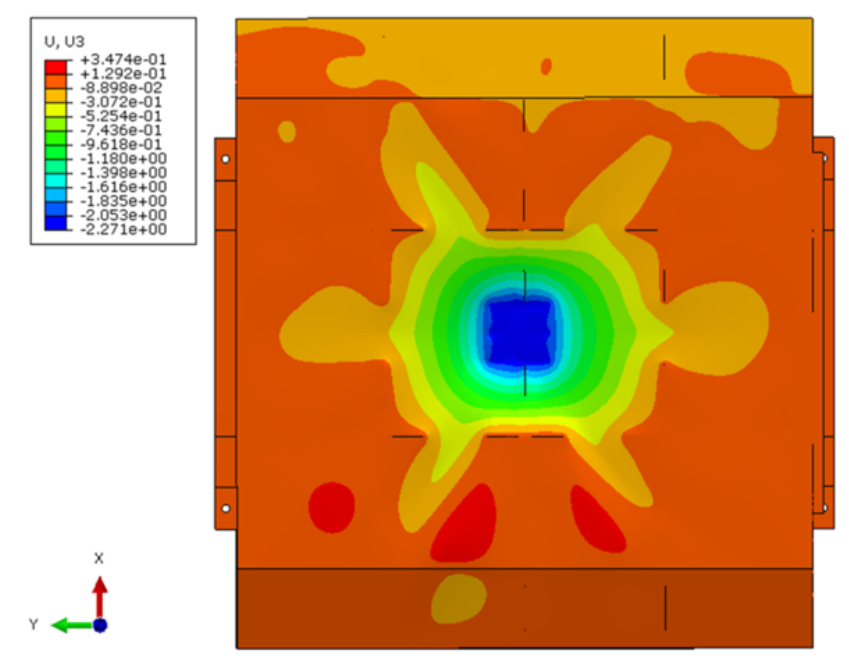

Figure 19. Residual Dent in Tank 202, Post-test FEA 
The acceleration versus time history for Tank 202 is shown in Figure 20, both for the test and for the post-test FEA. The measurements were made by the left side sill accelerometer, BA2LX. There is relatively good agreement between the test and the FEA. In the test and the analysis the baffle beneath the impacted location buckles almost immediately upon contact. As the baffle directly beneath the impactor folds, the inside face of the bottom surface of the tank comes into contact with it, permitting the load to rise again. The accelerations measured during the impact test of Tank 202 are considerably higher than those measured for Tank 232. The impact event is also over in less time than the impact event of Tank 232.

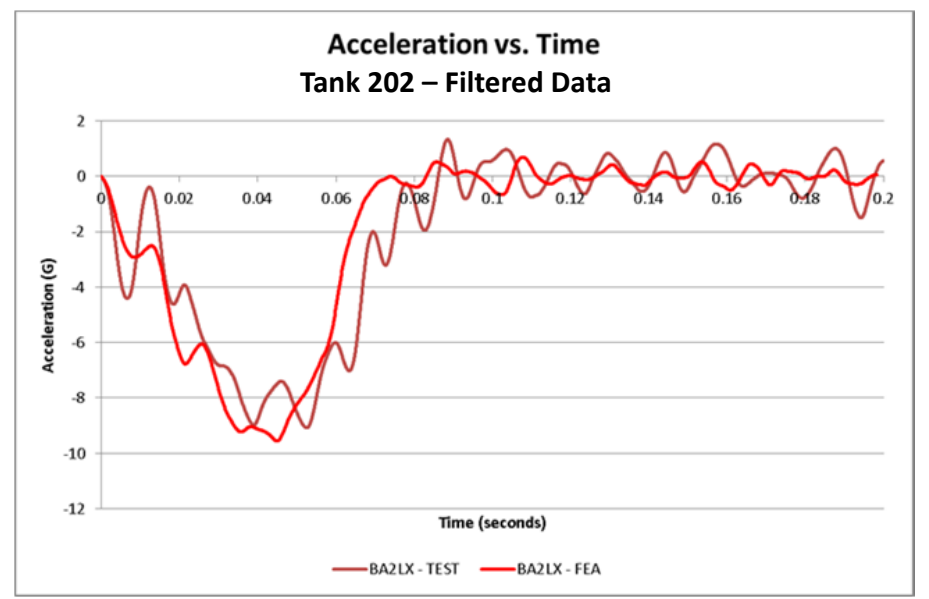

Figure 20. Acceleration versus Time, Tank 202 Test and FEA (Post-test)

The displacement versus time history for the impact cart in both the analysis and the test is shown in Figure 21. The displacement data is obtained through double-integration of the left side sill accelerometer, BA2LX. In the test, the dent reached a maximum depth of approximately 3.6 inches before the cart began rebounding from the tank. In the post-test FE model, the maximum dent depth is approximately 3.4 inches before the cart is rebounded. The difference between test and FEA is approximately $5.5 \%$ of the measured value.

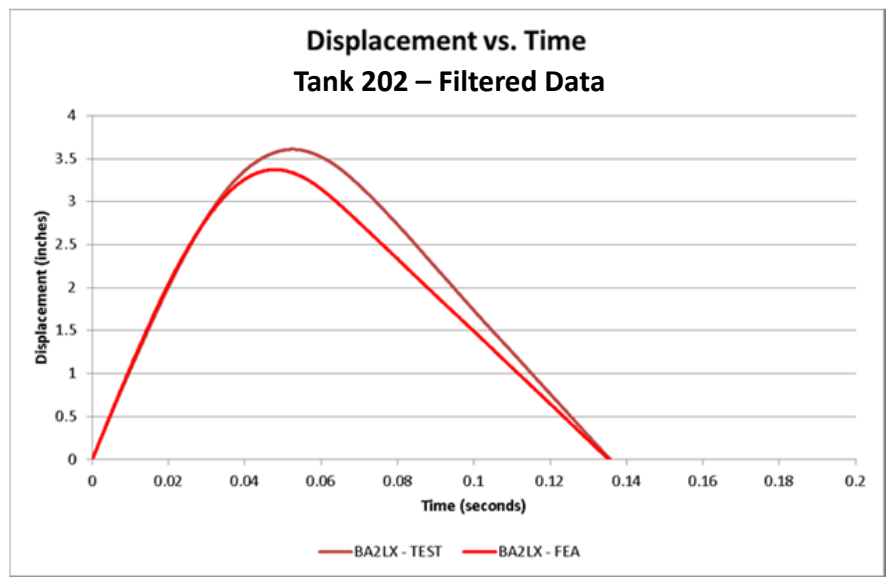

Figure 21. Displacement versus Time, Tank 202 Test and FEA (Post-test)
Following the impact test, Tank 202 was cut open to permit examination of the internal deformations. The impactor struck this tank at the center of a baffle. The initial drop in load observed in both the test and FE accelerations prior to 0.01 seconds, shown in Figure 20, is associated with this baffle and its attachment brackets immediately folding up. Because the baffle remains in contact with the underside of the bottom sheet, the acceleration climbs as the tank offers increasing resistance to further indentation. This behavior was captured by the post-test FE model. The deformed shape of the baffle is shown for both the model and the actual tank in Figure 22.

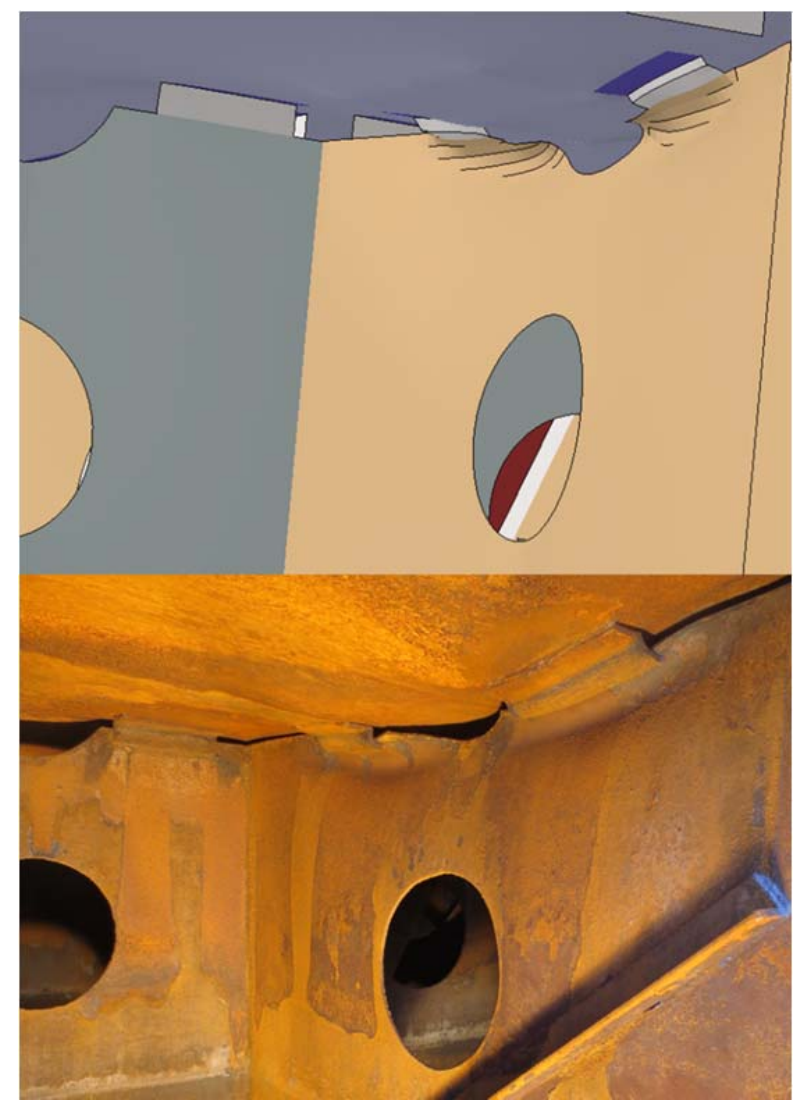

Figure 22. Post-test Baffle Deformation of Tank 202. Interior Views of Baffle and Bottom Fuel Tank Connections at Point-of-Impact; Image of FEA (Top) and Test Specimen (Bottom)

\section{SUMMARY}

On October 8, 2013 and October 9, 2013, the FRA conducted two impact tests of conventional passenger locomotive fuel tanks at the TTC in Pueblo, Colorado. The test setup was designed to impart a blunt impact to the bottom of each fuel tank. The two test specimens were fuel tanks of different designs from retired F-40 passenger locomotives. Each fuel tank was emptied of fluid and mounted on a crash wall with the bottom surface exposed. A rail cart modified with a "rigid" indenter, head size 12 inches by 12 inches, was released to impact the center of the bottom of each fuel tank at about $6 \mathrm{mph}$.

In the first test, Tank 232 was impacted by the indenter at $4.5 \mathrm{mph}$. The maximum residual indentation on the bottom of 
the tank measured approximately 5 inches. The tank deformed across the middle longitudinal span of the tank into a diamondshaped indention. In the second test, Tank 202 was impacted by the indenter at $6.2 \mathrm{mph}$. The maximum residual indentation on the bottom of the tank measured approximately 1.5 inches. The bottom of the tank deformed with an " $X$ " shape spanning out from the location of square indenter at the center of the tank.

Post-test autopsies revealed the deformation of the interior structures, i.e. baffles and attachments. There was no damage to the baffles in Tank 232. Deformation to the interior structure of Tank 202 was limited to the baffle directly beneath the impact location, which folded in about 4 inches near the impact location. Material coupons were cut and tensile testing performed. As one would expect, reliable material and geometric data are vital to accurate model estimates. In addition, the flexibility of the cart needs to be explicitly accounted for in this test.

\section{LESSONS LEARNED}

One of the primary reasons for performing this first series of tests on retired fuel tanks was an evaluation of the test setup, including fixturing and instrumentation. While both tests were successful in measuring the acceleration-time histories of the impacted tanks, there were several areas of improvement that will be incorporated into any future tests of this sort. These "lessons learned" are summarized in this section.

Because Tank 232 was the first of the tanks to be tested, some minor testing details identified through the conduct of the first test were immediately incorporated into the conduct of the test of Tank 202. Specifically, the actual impact speed of 4.5 mph was further below the target $+/-1$ mph speed range than anticipated. Examination of the speed-time history measured by a radar gun during the test revealed that the cart began to decelerate prior to striking the tank. Because slab track is used just prior to the impact wall, dirt had built up between the rail's flange and the side of the concrete, causing an area of higher friction than in pure wheel-to-rail contact. Prior to conduct of the test for Tank 202, the dirt was cleared away and the impact speed was closer to the targeted speed. There still remained a decline in the speed in the last few feet before the wall that is still being investigated.

During the test of Tank 232, there were several issues with triggering the instrumentation. The accelerometers on the cart as well as the high-speed cameras were designed to be triggered by a simply designed mechanism of contacts on the bottom of the cart and the ground just in front of the crash wall. During the test, two of the tape switches did not trigger with the existing contact setup. This appeared to be due to an overlap of switches on top of each other and too soft of a support surface. Modifications were made to the impact surfaces for the test of Tank 202 to create a more precise impact of each switch.

Finally, during post-processing of the test data it was apparent that the impact cart did not act as a "rigid" structure under the test conditions, as initially expected. This resulted in more noise being measured by the accelerometers than expected. In particular, the accelerometers mounted in the center of the car were more susceptible to noise than the accelerometers mounted on the side sills of the cart. To account for the flexibility in the cart, the post-test FE models have required modeling of the impact cart as a deformable body rather than a single rigid body with the full mass of the impact cart associated with it. While this enables the accelerometer data to be directly compared between the instrumented location on the cart and a corresponding location in the FE model, it poses a challenge to comparing the impact force, as the entire mass of the cart cannot be associated with a single point.

Each of these technical details is being documented and will be used to improve the testing setup for future blunt impact tests. Future tests include testing of new DMU fuel tanks. For such tests, the material properties and geometry of the tanks will be known and FE models can be developed to plan for tests. The results will allow for different fuel tank designs to be better understood under dynamic loading conditions.

\section{ACKNOWLEDGEMENTS}

The fuel tank research is part of the Equipment Safety Research Program sponsored by the Office of Research and Development of the FRA. This work is monitored by Program Managers in the Office of Railroad Policy and Development. FRA staff at TTC helps to coordinate efforts between FRA, Volpe and TTCI.

The authors would like to acknowledge Volpe Center colleagues, David Tyrell for his ongoing technical advice and support in the research discussed in this paper, Patricia Llana for her assistance in analyses and developing the FE model of the impact cart and Laura Sullivan for her assistance with test plans.

\section{REFERENCES}

[1]. U.S. Department of Transportation, Federal Railroad Administration, Code of Federal Regulations, Title 49, Part 238, Appendix D- "Requirements for External Fuel Tanks on Tier I Locomotives".

[2]. Jacobsen, K., "Fuel Tank Crashworthiness: Loading Scenarios," American Society of Mechanical Engineers, Paper No. JRC2011-56077, March 2011.

[3]. Jacobsen, K., Llana, P., Carolan, M., Sullivan, L., "Fuel Tank Integrity Research: Fuel Tank Analyses and Test Plans," Proceedings of the 2013 ASME/IEEE/ASCE Joint Rail Conference, JRC2013-2425, April 2013.

[4]. Jacobsen, K., Llana, P., Carolan, M., Llana, P., "Test Requirements of Locomotive Fuel Tank Blunt Impact Tests," Proceedings of the 2013 ASME Rail Transportation Division Fall Technical Conference, RTDF2013-4701, October 2013.

[5]. Muhlanger, M., Llana, P., Tyrell, D. "Dynamic and QuasiStatic Grade Crossing Collision Tests," American Society of Mechanical Engineers, Paper No. JRC2009-63035, March 2009.

[6]. Abaqus version 6.12. Dassault Systems Simulia Corp, Providence, RI, 2012. 